Received $7^{\text {th }}$ April 2020

Accepted $2^{\text {nd }}$ August 2020

Link to DOI:

10.25220/WNJ.V04.i1.0005

Journal Website:

www.worldnutrijournal.org

\section{Efficacy of branched-chain amino acid to increase muscle strength in chronic heart failure patients: an evidence-based case report}

\author{
Karin Wiradarma ${ }^{1}$, Lily Indriani Octovia ${ }^{1}$ \\ 1. Department of Nutrition, Faculty of Medicine, Universitas Indonesia, Dr. Cipto Mangunkusumo \\ Hospital, Jakarta, Indonesia.
}

\begin{abstract}
Background: Chronic heart failure (CHF) patients can fall into cardiac cachexia (CC), which is marked by the decrease of muscle mass and strength. Cardiac cachexia decreases the functional capacity and quality of life also increases the length of stay, medical fees, complications, and mortality rate. Branched-chain amino acid (BCAA) accounted for $35 \%$ of amino acids that build the muscle. We hope that BCAA supplementation can increase muscle strength of CHF patients, especially the elderly who is more prone to fall into CC. Thus, we performed an evidence-based case report to seek an opportunity of BCAA supplementation to an elderly with CHF.

Objectives: To determine the efficacy of BCAA supplementation on increasing muscle strength in CHF patients.

Methods: Literature searching of the evidence-based case report was performed on Pubmed, Cochrane, and Scopus according to the clinical query. Screening on title, abstract, and full text was done based on eligibility criteria (meta-analysis or clinical trials, suitability to clinical questions, English language, full-text availability, and human studies), followed by duplication filter and critical appraisal.

Results: A randomized-controlled trial was found, but it didn't find a significant difference between the experimental and control groups.

Conclusions: BCAA supplementation doesn't give a significant improvement in muscle strength in CHF patients.
\end{abstract}

Keywords branched-chain amino acid, chronic heart failure, cardiac cachexia, muscle mass, muscle strength

\section{Introduction}

Heart failure has become a rising global issue with more than 62 million people affected. ${ }^{1}$ The mortality risk is $35 \%$ in the first year after diagnosis. ${ }^{2}$ Despite all current and advanced treatment, the 5-year-

\section{Corresponding author:}

Lily Indriani Octovia

Department of Nutrition, Faculty of Medicine,

Universitas Indonesia

Email: lily.indriani@gmail.com mortality rate is still high and increasing. ${ }^{1}$ The high mortality rate allegedly related to anorexia, inflammation, and hypermetabolism that occur in CHF, which will result in weight loss and loss of skeletal muscle mass, called CC. This condition not only occurs in the skeletal muscle but also cardiac muscle, ${ }^{3}$ and was estimated to affect between 8 to $42 \%$ of patients with $\mathrm{CHF}$, which responsible to increase mortality rate as high as $20-30 \%$ at 1 year. Therefore, it is crucial to preserve and increase muscle mass and strength in CHF patients. ${ }^{4}$

Branched-chain amino acid supplementation has been shown to enhance muscle's mitochondrial biogenesis by activation of the mechanistic target of 
rapamycin kinase (mTOR) signaling. Several studies have found that BCAA can increase the synthesis of protein, reduce the protein breakdown, and increase muscle mass in the elderly and several catabolic states such as burn and trauma. ${ }^{5}$ Therefore, it is hoped that this report can provide consideration for giving BCAA supplementation to alleviate cardiac cachexia.

\section{Clinical Scenario}

Mr. B, 60 years old, comes with exertional dyspnea which worsens since a week ago. He complains about orthopnea, fatigue, and ankle edema. He was diagnosed with HF with reduced ejection fraction 5 years ago, after recovering from a heart attack. The patient complains about anorexia and low intake, which makes his weight drops from $70 \mathrm{~kg}$ to $65 \mathrm{~kg}$ in 6 months. His height is $170 \mathrm{~cm}$, with a calculated body mass index of $22.49 \mathrm{~kg} / \mathrm{m}^{2}$. Handgrip strength found slightly decreased. Other than having an elevated CRP (6 mg/dL) and high blood LDL (170 $\mathrm{mg} / \mathrm{dL})$, the other lab result is normal. After treated with standard medication for CHF for several days, now the patient is stable and ready to be discharged. Based on this clinical scenario, a question arises whether BCAA supplementation will be effective in preserving and increasing muscle mass and strength in CHF patients?

\section{Methods}

Literature searching was performed on Pubmed, Cochrane, and Scopus according to the clinical question on the $14^{\text {th }}$ of May 2020. The keywords used were "branched-chain amino acid", "heart failure", "cardiac cachexia", "muscle mass", and "muscle strength". Screening on title, abstract, and full text was done based on eligibility criteria (metaanalysis or clinical trials, suitability to clinical questions, English language, full-text availability, and human studies), followed by duplication filter and critical appraisal was shown in Figure 1. A critical appraisal is done based on the Center of Evidence-Based Medicine, The University of Oxford for RCT.

\section{Results}

Following the search strategy, one original article was eligible for this evidence-based case report. The design and summary of the selected article are available in Table 1. Both groups had significant improvement in decubitus intolerance, fatigue, dyspnea, and muscle strength. But other than a marked reduction of hip circumference in the experimental group, there was no difference statistically between the control and intervention group in the rest of anthropometric variables, body composition, muscle strength, and physical endurance.

\section{Discussion}

Studies conducted by Juarez et $\mathrm{al}^{6}$ had a clear clinical question (PICO) and corresponded to keywords accordingly. The control and intervention groups were similar at baseline, except for fatigue and cancer history. The assignment of patients to treatments was randomized, but not blinded. Aside from the allocated treatment, the groups were treated equally. Drop-out subjects were not analyzed. Overall, we found this study valid, although there will still be bias because the assignment is not blinded.

Although there are many studies about protein and amino acid supplementation in CHF and CC, there is no other study about BCAA supplementation. Apparently, this is the first. This study did not find any impact on muscle mass and strength with BCAA supplementation. The result is the same with a study that did not find a difference in functional capacity after $5 \mathrm{~g}$ /day supplementation of carnitine. ${ }^{6}$ A longitudinal cohort also showed that higher protein intake was not associated with protection against muscle loss in the elderly. Even so, other studies found positive results with amino acid supplementation. A study gave $8 \mathrm{~g} /$ day of essential amino acid and found improvement in cardiorespiratory fitness. Other studies found amelioration of body weight and muscle mass after giving supplementation of $600 \mathrm{kcal}$ and $20 \mathrm{~g}$ of protein per day. ${ }^{7}$

There are several presumptions about this study's result. First of all, perhaps the participants were not in a depleted state of BCAA, so they could 
not benefit from BCAA supplementation. ${ }^{7}$ identify the efficacy of BCAA to prevent and treat Secondly, excess of BCAA in the blood can cause a CC in CHF. rise in BCAA's metabolite, branched-chain- $\alpha$ ketoacid (BCKA) which can cause elevated levels of ammonia in blood and result in metabolic acidosis. This condition can create mitochondrial dysfunction, oxidative stress, and harm myocyte. ${ }^{1}$ Thirdly, the hyper catabolic state of heart failure patients may cause a decrease in gastrointestinal tract absorption, thus BCAA can not be absorbed optimally. This is seen from the increasing level of BUN and urea in the intervention group. ${ }^{6}$ Last but not least, it is plausible that in the elderly with cardiac cachexia, BCAA supplementation is not enough to increase muscle mass without strength training. ${ }^{7}$ However, strength training did not include in other studies, they only gave protein or amino acid supplementation. This study is the first to accommodate strength training with BCAA supplementation. The limitation of this study is the assignment is not blinded, and perhaps it will be fairer to look at the true effect of BCAA supplementation if the assignment of the groups doesn't involve strength training. For example, the experimental group is given BCAA supplementation, and the control group is not.

\section{Conclusion}

Although we can not recommend BCAA supplementation for CHF patients to prevent $\mathrm{CC}$ in the present, more study and evidence are needed to

Table 1. Literature characteristic

\begin{tabular}{|c|c|c|c|c|}
\hline Article & Design & Population & Exposure & Results \\
\hline $\begin{array}{l}\text { Pineda- } \\
\text { Juarez et } \\
\text { al, } 2016^{6}\end{array}$ & $\begin{array}{l}\text { Randomized } \\
\text { controlled trial }\end{array}$ & $\begin{array}{l}66 \text { patients aged }>18 \\
\text { years old from the } \\
\text { heart failure clinic in } \\
\text { Mexico City who had } \\
\text { stable heart failure, no } \\
\text { myocardial } \\
\text { revascularization, } \\
\text { unstable angina, or } \\
\text { stroke in the previous } \\
3 \text { months, had no other } \\
\text { chronic illness which } \\
\text { contributed to a loss of } \\
\text { muscle mass, and able } \\
\text { to perform an exercise }\end{array}$ & $\begin{array}{l}\text { The intervention } \\
\text { group had a } \\
\text { personalized } \\
\text { diet, a resistance } \\
\text { exercise } \\
\text { program (RE), } \\
\text { and } 20 \text { grams of } \\
\text { BCAA per day } \\
\text { for } 3 \text { months. } \\
\text { Control group } \\
\text { only had a } \\
\text { personalized } \\
\text { diet and RE } \\
\text { program }\end{array}$ & $\begin{array}{l}\text { There were statistically significant } \\
\text { improvements in decubitus intolerance, } \\
\text { dyspnea ( } p=0.03 \text { ), fatigue }(\mathrm{p}<0.0001) \text {, and a } \\
\text { tendency to decreased dyspnea }(\mathrm{p}=0.07) \text { in } 2 \\
\text { groups, but there was no statistical difference } \\
\text { between the groups. } \\
\text { Muscle strength was increased by } 34.5 \% \text { in } \\
\text { the subjects ( } \mathrm{p}=0.08) \text {, with no difference } \\
\text { between groups. } \\
\text { Hip circumference in the experimental group } \\
\text { was decreased markedly than the control } \\
\text { group ( } \mathrm{p}=0.02) \text {. But the differences between } \\
\text { other anthropometric variables, body } \\
\text { composition, and physical endurance were } \\
\text { not statistically different between the two } \\
\text { groups. }\end{array}$ \\
\hline
\end{tabular}

*BCAA $=$ branched-chain amino acid 


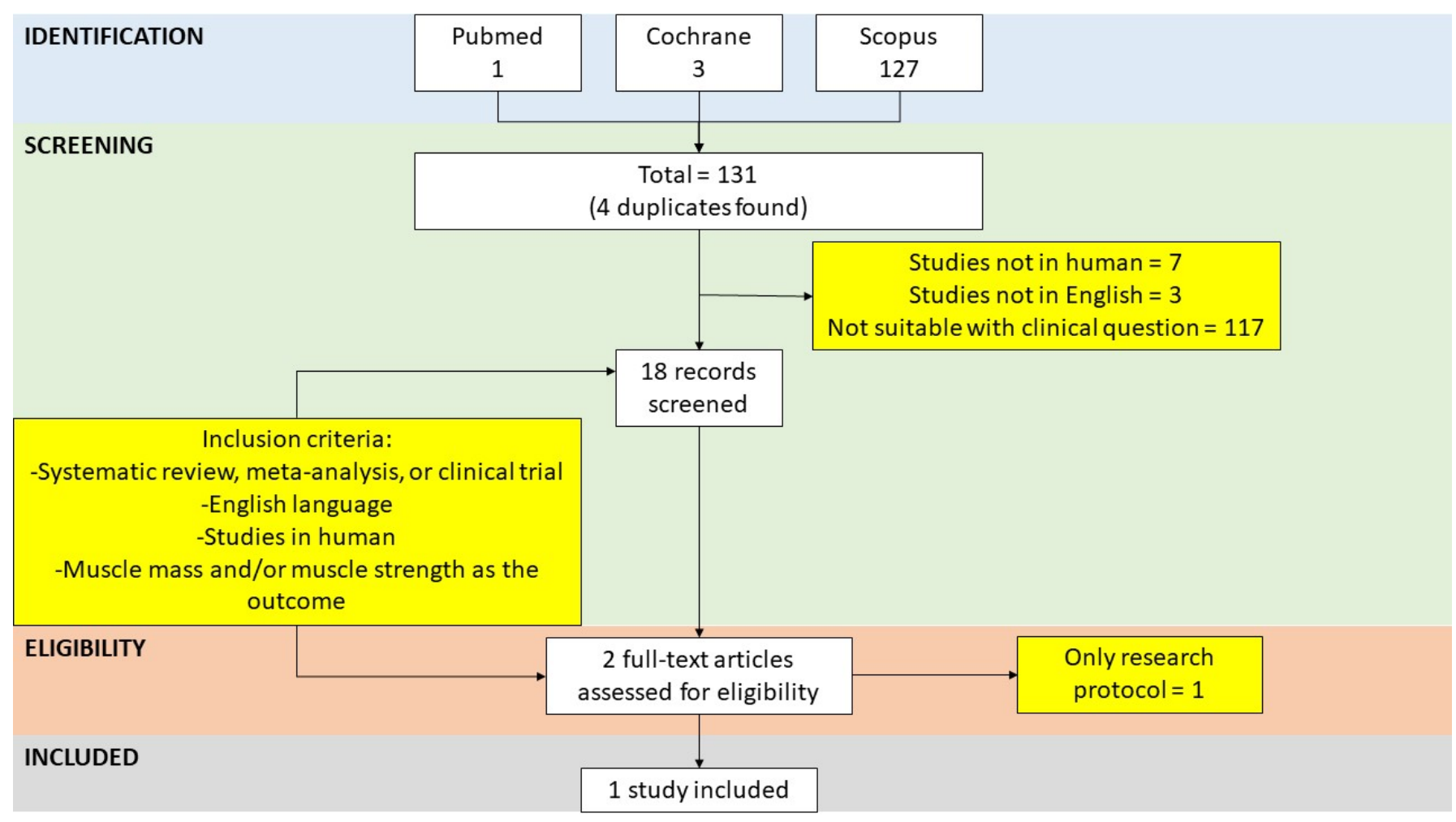

Figure 1. Flowchart of search strategy 


\section{Conflict of Interest}

Authors declared no conflict of interest regarding this article.

\section{Open Access}

This article is distributed under the terms of the Creative Commons Attribution 4.0 International Licence

(http://creativecommons.org/licenses/by/4.0/), which permits unrestricted use, distribution, and reproduction in any medium, provided you give appropriate credit to the original author(s) and the source, provide a link to the Creative Commons license, and indicate if changes were made.

\section{References}

1. Birkenfield AL, Jordan J, Dworak M, Merkel T, Burnstock G. Myocardial metabolism in heart failure: purinergic signalling and other metabolic concepts. Pharmacology \& Therapeutics. 2019;194:132-144.
2. Kim IY, Park S, Smeets ET, et al. Consumption of a specially-formulated mixture of essential amino acids promotes gain in whole body protein to a greater extent than a complete meal replacement in older women with heart failure. Nutrients. 2019;11(6):1360.

3. Lena A, Ebner N, Anker MS. Cardiac cachexia. European Heart Journal Supplements. 2019;21(L24-7).

4. Rolfe M, Kamel A, Ahmed MM, Kramer J. Pharmacological management of cardiac cachexia: a review of potential therapy opions. Heart Fail Rev. 2019;24(5):617-623.

5. Bifari F, Ruocco C, Decimo I, Fumagalli G, Valerio A, Nisoli E. Amino acid supplements and metabolic health: a potential interplay between intestinal microbiota and systems control. Genes \& Nutrition. 2017;12:27.

6. Juarez JAP, Ortiz NAS, Martinez LC, et al. Changes in body composition in heart failure patients after a resistance exercise program and branched chain amino acid supplementation. Clinical Nutrition. 2016;35(1):41-47.

7. Carbone S, Billingsley HE, Miguelez PR, et al. Lean mass abnormalities in heart failure: the role of sarcopenia, sarcopenic obesity, and cachexia. Curr Probl Cardiol. 2019;00:100417. 